\title{
The Recruitment of Psychiatrists in Mental Handicap
}

\author{
By D. A. Spencer, Consultant Psychiatrist, Meanwood Park Hospital, Leeds
}

In most parts of the country today it is often difficult or impossible to fill consultant vacancies in mental handicap. According to the DHSS there were 146 consultants in mental handicap in post in 1978 compared with 102 in 1968, an overall growth of 43 per cent, compared with 34.7 per cent in general psychiatry. Nevertheless nearly one quarter of posts were vacant on 30 September 1978. The number of new consultants in mental handicap required to replace losses from death and retirement is about 6 to 10 per year. If an expansion of 10 is to be achieved some 16 to 20 fully trained senior registrars will be required each year. For this 60 senior registrar posts will be needed, assuming that senior registrars have three to four years training. At the end of September 1978 there were 34 established senior registrar posts of which 9 were vacant.

Why are posts in mental handicap difficult to fill? The work has its attractive and unattractive sides. So has any job, and these must be put in proper perspective. Mental handicap can offer a satisfying and rewarding vocation.

About 30-35 per cent of mental handicap hospital residents, and many of the cases referred to psychiatrists in the community, require specialist services. These are needed for such problems as physical handicap, epilepsy, visual and auditory defects, severe behaviour and conduct disorders, communication difficulties and lastly mental illness, which affects 6-14 per cent of the mentally handicapped in hospital, in addition to those who show severe psychoneurotic disorders. Then there are the problems of the elderly mentally handicapped, the profoundly mentally and physically handicapped and those with neurological abnormalities, and the wider questions of epidemiology, aetiology and prevention.

\section{The attractive features of work in mental handicap}

Work in mental handicap has more attractive features than most doctors suppose. At present there is the attraction of plenty of vacant posts and good promotion prospects compared with some other specialties where a doctor's duties are predetermined and inflexible, work in mental handicap is to a considerable degree what the consultant makes it.

The field poses many challenges. There is the inherent difficulty of the subject, in which much awaits research and discovery. The relationships between mental handicap and psychiatric disorders call for more exploration. The emotional problems of the parents and relatives deserve closer study.

The consultant has other than clinical challenges to tackle. There are facilities and services to be improved and new and changing patterns of service to be developed. There is ample scope for teaching. Almost every patient in hospital will demonstrate some medical, psychiatric, psychological, social or educational problem. The same applies to mentally handi- capped people whom the psychiatrist treats in the community. Hence there are wide possibilities for research.

Because of the small number of consultants in the field all of those practising in it are likely to find themselves drawn into administrative and planning arrangements for the service. The consultant has therefore the opportunity to make his views heard. Mental handicap is still an-ill-understood and even a taboo subject and the consultant has an essential part to play in wider health education.

The consultant in mental handicap will see fewer patients than his colleagues in general psychiatry, and many of them will have long-term problems which he will be helping over many years, especially as the pattern of service moves away from crisis intervention model.

\section{Unattractive points of work in mental handicap}

No worthwhile job is easy, and work in mental handicap has its unattractive points. These can be a challenge in themselves and many of them would disappear or become more bearable if the number of psychiatrists in the field increased.

At present professional isolation and loneliness are disadvantages. With approximately 150 consultants, mental handicap is a small specialty. A consultant can be working single handed, the only specialist in that field for a hospital or Area Authority. He is working in hospitals which are outside the mainstream of medicine and out on a limb in psychiatry. The fewer the specialists, the greater their isolation and loneliness.

Isolation tends to result in the low prestige of the consultant in mental handicap. Under the 'cogwheel' system of medical organization, because of their small numbers, consultants in mental handicap will be 'latched on' to a Division of Psychiatry or Paediatrics. They should press for separate seats on their Medical Executive Committees. Because of their weak power position, consultants in mental handicap have suffered humiliation to an extent to which consultants in major general specialties would not be exposed and would not tolerate for a moment.

Regrettably, consultants in mental handicap still meet prejudice and treason among colleagues within their own profession. Even some psychiatrists view mental handicap with an amused derision and give the impression that it would be an insult and beneath their dignity to have to deal with it. Such prejudice ill becomes psychiatrists as psychiatrists, doctors and citizens. It is a sad reflection on undergraduate and postgraduate medical education. Perhaps no more can be expected as long as mental handicap receives so little attention in medical education.

Remuneration is not likely to be a dominant theme in the mind of the psychiatrist, otherwise he would not be practising in that specialty. It is fair to argue that the con- 
sultant in mental handicap should not be penalised financially in comparison with other consultants. Related to remuneration is private practice, for which by the nature of the work there is little scope in mental handicap.

At present consultants in mental handicap carry a considerable case load, above that advised by the College. A consultant is expected to be on call for psychiatric emergencies, arranging urgent admissions and giving advice. The fewer the consultants in the specialty the less chance there is of sharing duties. The demand for 'on call' availability all the time is stressful and limiting to the life of the doctor, his family and his home.

Because of the apparently low position of mental handicap in the pecking order of priorities in the National Health Service, too many consultants in mental handicap work with inferior and inadequate facilities and services. The inefficiency and time-wasting this causes are tiresome and frustrating.

Mentally handicapped people, and especially those who come to psychiatric care, are not at first sight the most acceptable of patients. The severely mentally handicapped are often pitifully disabled, incoherent, noisy and dirty. The mildly handicapped are sometimes rude, crude, threatening and frightening. Such patients arouse strong emotions in those around them. Professional staff are affected, as are laymen. It is this repulsiveness of many mentally handicapped which should inspire dedication to enhance their dignity as human beings. Even among doctors, personalities strong enough to devote themselves to such patients will be few and far between.

Consultants in mental handicap cannot cure patients in the same sense as surgeons, physicians and general psychiatrists. They examine and diagnose their patients, but in their management the consultant is usually acting as a "coordinator' and an 'enabler', who brings many services to bear to help the patients within an overall strategy which is frequently agreed in conference with other members of a professional team. Some doctors may suffer from a lack of perceived success in this role. Others will welcome being a liaison consultant.

The vogue for multidisciplinary meetings and decision making is seen as a threat by some consultants. But in practice no NHS consultant works in isolation. Neither the surgeon nor the physician can function without the support of other departments and colleagues working as a team.

Uncertainty about the role of the consultant in mental handicap and about the future of health service provision for mental handicap may also deter recruitment to the specialty. But hospitals for mental handicap are likely to remain in the foreseeable future. The specialist needs of the mentally handicapped can be clearly stated: the psychiatrist's role is in the psychiatry of mental handicap.

\section{Stimulating recruitment}

There are possible but no certain solutions to the shortage of consultants in mental handicap. First are efforts to maintain mental handicap as a viable specialty. A full complement of specialists in mental handicap would improve the attractiveness of the specialty. The organization of doctors working in it would be more active and with adequate staff advances in the development of the service would be achievable.

Second, should this be impossible, are ways of re-deploying psychiatric consultants generally to cover mental handicap.

More and more rotational training schemes in psychiatry at registrar and senior registrar level have been introduced. They are now regarded as mandatory by the Royal College of Psychiatrists, though there has been some argument as to the length of the mental handicap secondment. More trainee psychiatrists will have experience in it. Proleptic appointments, and guarantees of promotion to suitable candidates prepared to work in mental handicap have been proposed and are already applied on a limited scale. The establishment of more academic departments in mental handicap has been mooted; one chair in mental handicap is already in being, and elsewhere lecturers, if not professors, might be appointed in the main teaching centres. The award by the College of a Certificate of Specialist Training in the Psychiatry of Mental Handicap to those with proven experience in the specialty would improve its status, maintain its standards and emphasize its psychiatric importance.

Financial inducements to attract doctors into unpopular appointments can be two-edged weapons. They are difficult to apply fairly, and they stigmatize a specialty and a post. New patterns of care for mentally handicapped people away from hospital to community-orientated services await full development. In theory such a service should be more attractive to consultants. There is often reference to the employment of more women doctors, perhaps on a part-time basis.

If it continues to be impossible to induce adequate numbers of psychiatrists prepared to specialize in mental handicap, a re-allocation of psychiatrists' responsibilities will be inevitable. Joint appointments between general psychiatry and mental handicap have been adopted in Scotland and joint posts in mental handicap and child psychiatry are found in parts of England; it has been strongly contended that this has not affected the quality of the care given to the mentally handicapped. The few existing specialists in mental handicap might be employed on a wider advisory level as Regional Psychiatrists in mental handicap. General psychiatrists would have to take a greater responsibility for patients with intelligence quotients in the 50 to 70 range. In mental handicap hospitals more non-consultant doctors, for example hospital practitioners, could be employed. The social services would have to accept at least a joint responsibility for many residents not strictly in need of psychiatric care.

\section{Conclusion}

The strength and justification of the consultant in mental handicap is his dedication to his patients on a full-time basis. He has often to act as defender as well as helper of mentally handicapped people and is the only specialist always able and willing to give them priority. 